Peer-Reviewed Article

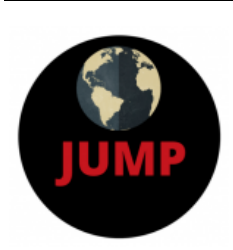

OJED

ISSN: 2574-3465 Print/ ISSN: 2574-3481 Online

Volume 5, Issue SI (2021), pp. 1-12

(C) Journal of Underrepresented and Minority Progress http://ojed.org/jump

\title{
COVID-19: How Will Historically Underrepresented Groups Fair in the Job Market?
}

\author{
Emmanuela P. Stanislaus \\ Florida International University, USA \\ Lynell S. Hodge \\ Amanda Wilkerson \\ University of Central Florida, USA
}

\begin{abstract}
The inability of college students to traditionally interact with post-secondary personnel might have unintended limitations on career readiness and postgraduation outcomes. Novel Coronavirus (COVID-19) persists as a healthcare concern; however, it has and continues to impact various sectors. In higher education, the global pandemic has affected university operations from in-person to virtual based support. However, little is known about the unintended consequences of collegiate support services' virtual operations, such as career services. This conceptual paper will objectively analyze the potential inequities of the COVID-19 pandemic on job prospects and social capital for students of color. Recommendations for the economic and social factors are discussed. In addition, this paper may contribute to disrupting the overlooked consequences of offering college services remotely.
\end{abstract}

Keywords: COVID-19, employment, social capital, underrepresented students 


\section{INTRODUCTION}

Novel Coronavirus (COVID-19) has disrupted every industry and changed how college students and graduates perceive job opportunities and navigate the job market. The Center for Disease Control and Prevention estimates that over 215,000 Americans will die from COVID-19 by October 15th. Additionally, millions of people are jobless, increasing the unemployment rate to $13.3 \%$ in May 2020 (Bureau of Labor Statistics, 2020). Recent unemployment figures have surpassed the Great Recession's peak and have impacted women and Black populations at higher rates (Kochhar, 2020). Rising cases and deaths led most higher education institutions to take unprecedented actions to transition campus operations and courses to virtual formats quickly. These current uncertain times require examining the higher education landscape and how minoritized student populations may be impacted.

Pursuing a college education is often tied to the goal of attaining a high paying job (Pascarella \& Terenzini, 2005). For example, the 2019 Higher Education Research Institute Freshmen Survey revealed that $83.5 \%$ of freshmen choose to attend college to access better-paying jobs (Stolzenberg, et al., 2020). College graduate employment has traditionally been linked to college career centers but is also associated with relationships built with faculty and administrators. The impact of COVID-19 on the employment outcomes of current college graduates is not yet known.

Research has pointed to the influence that faculty have on student success (Museus \& Neville, 2012; Pascarella \& Terenzini, 2005). Persistence is shaped and impacted by faculty interactions and their notions of care (Guiffrida, 2005; Museus \& Neville, 2012; Pascarella \& Terenzini, 2005). Scholars have reported that students of color found college classroom environments unwelcoming (Museus \& Neville, 2012; Rankin \& Reason, 2005). Furthermore, Guiffrida (2005) found that Black students may not reap the benefits tied to faculty interaction in a traditional campus setting. This is particularly important as faculty relationships impact social capital in terms of access to scholarship, internship, and career opportunities (Parks-Yancy, 2012). Today, in this new virtual mode of learning and engagement, it may be more difficult for underrepresented students to build critical relationships that could lead to the high-paying careers they initially seek.

Although research on the impact of COVID-19 in higher education is emerging, we find it imperative to explore this topic to shed light on the potential widening of White and minoritized college students' disparities. This conceptual paper adds to the body of literature that centers on understanding college students' experiences of color. Further, this paper takes 
a unique approach in examining how COVID-19, remote class instruction, and operations could potentially impact social capital production. This conceptual article draws from Yosso (2005) work that explores cultural capital among marginalized groups. Yosso's (2005) community cultural wealth model expands Bourdieu's (1977), which centered on social capital ideas related to class and whiteness. Consequently, interpretations of Bourdieus' (1977) work led to the use of a deficit lens to view the capital students of color possess; however, Yosso (2005) counters that narrative.

This conceptual paper argues that remote instruction will have unintended implications on student success and graduate employment outcomes, particularly for minoritized student populations. We begin by discussing the important role that staff and administrators play in fostering student success, then exploring aspects of cultural capital and how it relates to employability. The remainder of this paper focuses on discussion, implications, and conclusion.

\section{CONCEPTUAL FRAMEWORK}

As we consider navigating an emerging scenario such as COVID-19, practitioners should rely on literature to ground decision making. Early reports highlight a widening achievement gap for students of color who are navigating how to keep up academically. School systems report staggering numbers of students who do not have computers at home or reliable internet (Rothstein, 2020). As such, approaches to meet students' needs in a remote environment present compounding challenges that need to be explored, particularly as it relates to Black student needs. Delgado (2003) provides a precise charge to challenge the academy to consider that race is a struggle that must expressly be addressed to make meaningful experiences. Therefore, the authors' mused-- how can administrators meet student needs when the crux of institutions functionality has radically shifted?

\section{Role of staff}

The authors acknowledge that COVID-19 presents several challenges to higher education, particularly in terms of moving from in-person instruction to remote learning. However, administrations must be agile in response to address marginalized student needs holistically. One recommendation is to recognize students of color may struggle with persistent self-doubt in what we now would describe as a traditional in-person environment (Rice et al., 2013). Student self-doubt suggests students may not ask for help or recognize help is available to them. Similarly, a research study found that unless students have a stake in the outcome, their chances for 
disengaging increases, which is particularly relevant in online settings (Maurino, 2007). Bell (1992) found that while students of color may feel disconnected from the institution, they will learn from those who will teach them. Thus, fully activating and leveraging relationships between students and administrators and/or students and faculty is critical now more than ever.

Academic motivation of minoritized students is an emerging topic of interest; the academy has not collectively addressed race related to student success; however, psychological literature documented the importance of noncognitive factors as powerful resources to utilize (Roksa \& Whitley, 2017). We mention the lack of understanding of the disparity of information about students of color and challenge readers to think of these concerns as more than a thought exercise rather as an opportunity to close these gaps. Educational access, persistence, and graduation of students of color draw on an interdisciplinary accession to problem-solving (Yosso, 2005). One crucial factor to consider is transitional challenges to college, which are exacerbated by negative racial environments that are ever-present for Black students (Fischer, 2007). The authors would venture to surmise COVID-19 further complicates any policy development.

\section{Community Cultural Wealth Model}

The need to reevaluate delivery of engagement with Black students is paramount during the pandemic, which is no surprise given the difficulties involved with engagement prior to COVID-19. Navigating the hierarchical structure of higher education has historically presented exclusionary practices (Lang, 1984). As the academy reports out successes, the structure continues to present residual effects of gatekeeping. Critical race theory (CRT) examines the effect of racism, whether social structures, praxis, and discourse are implicitly and explicitly designed to be racist (Yosso, 2005). Utilizing a CRT lens provides an immediate source to interpret the preliminary gaps the academy is seeing during the pandemic. This critique keeps higher education institutions honest to acknowledge unintended or more directly unintentional barriers that remote instruction and operations present. CRT critique of higher education challenges administrators to discuss and answer what these barriers are critical. Yosso (2005) further developed CRT and designed a model that captures the talents, strengths, and experiences that students of color bring with them to their college environment. Yosso's (2005) model assesses the intersection of race and access to resources. Thus this model will be utilized to help frame the response to students' education in a remote setting.

With these concerns in mind, it is imperative to center decisions within a framework that focuses on the complexity of race, educational 
disparities, and access by employing Yosso's (2005) advancement of the community cultural wealth model. This framework is an anti-deficit model that recognizes and celebrates various forms of capital that students of color bring to college settings. Yosso (2005) accounts for the following capital: familial, social, navigational, resistant, linguistic, and aspirational. This framework fundamentally challenges and assesses systems that do not account for students' experience, which is necessary as we consider adverse impacts in a remote environment: "Social capital can be understood as networks of people and community resources; [these] peer and other social contacts. Navigational capital refers to the skills of maneuvering through social institutions. Historically, this infers the ability to maneuver through institutions" (Yosso, 2005, p. 79-80).

Additionally, Yosso (2005) conceptualized this model to account for the talents, strengths, and experiences that students of color bring with them to their college environment. The significance of activating social and navigational capital for students is to allow them to see their potential. Academic environments are strongly encouraged to be designed to allow students to build the skills (Schoenacher, 2009). These skills are crucial as it promotes information sharing, making connections, and developing relationships. As previously mentioned, relationships play an important role in Black student success. Relationships are essential because this requires the student to trust that the exchange will be reciprocal. Creating pathways to build these positive relationships further creates socialization where all parties (students, faculty, staff, administrators) are attuned and aligned to student success (Yosso, 2005). The navigational focus has to then shift from the student's motivation to institutions ensuring they sufficiently constructed access to staff and other beneficial resources in a remote environment.

\section{Future Gains}

It is important to note that students can often access academic resources, employment opportunities, internship, or scholarship information through the relationships they have forged with faculty and staff. Social capital can be leveraged for a number of student needs such as career, campus organizations, university's career resources, etc. (Parks-Yancy, 2012). These interactions create opportunities for students that have lasting positive effects and improve their overall academic experiences. To lessen the gap in a remote environment, institutions must consider remote instruction could alter student efforts and their social capital resources (Rosenbaum et al., 1999). To put it plainly, social capital affects college students' ability to achieve their career goals (Guiffrida, 2005; Museus \& Neville, 2012). Researchers Singh et al. 
(2008) found that social interactions and work experiences affect career trajectories throughout work life. Subsequently, it is important not to treat academic success and career readiness as two separate college students' experiences. Much like academic success, employability is an important outcome. Employability focuses on self-management and strongly urges students to take responsibility for integrating in and out-of-class experiences when they begin to look for work (Helens-Hart, 2019). This begs the question of how we can engage students NOW when we no longer can encourage students to visit our office or recommend resources based on the in-person meetings.

In summary, faculty and staff have unique roles that have benefitted students of color employability. Even in traditional settings, relationships with college administrators have been complicated for students of color to cultivate. Now that colleges have moved to remote operations, it is expected that the gaps are exacerbated, thereby causing additional barriers to increased social mobility and employment opportunities. These challenges should be of particular interest to institutions, given the increase in accountability for student success. In order to address this issue, one must engage in discussions and share implications for institutional agents of social capital.

\section{DISCUSSION/IMPLICATIONS}

The need to support underrepresented collegiate student populations with career services is critical. For many years, professionals in the field have developed strategies to increase student job searchers' social capital through in-person mentoring (Amundson et al., 2009; Engelland, 2000; Miller \& Brown, 2005). Yet, COVID-19 has significantly impacted the delivery of face to face support services. With the reduction of place-based in-person support tied with concerns for supporting underrepresented students, the challenge now becomes how career services can enhance its delivery. Earlier iterations of professional competencies emphasized developing programs to assist said students. However, there is a need to develop career service competencies and pedagogical practices that can support learners without regard to the location for which they receive services. That is how are professionals able to help students on and off the campus? Furthermore, in supporting students with career services, it requires further developing professional competencies that will allow professionals to be effective facilitators of support in the era of click and connect. Thus, in addressing the aforementioned problem, we set out to explore how professionals can promote career support in a virtual environment for underrepresented students, particularly Black students. It should be noted that the remainder of this section will be divided into three 
distinct categories of thought. First, we will review salient work that speaks to how Black college students can be supported. Another area for which we will provide insight is on best practices for engaging students in virtual environments. Finally, we will share literature where researchers analyzed providing career services in a non-traditional manner. The approach to providing the information mentioned above will offer various viewpoints on how this current work might discuss and possibly validate a series of standards that can be used in virtual environments as guidance for future career resource strategies for African American students.

Studies in recent decades have explored the experience of educated Black students (Gray et al., 2013; Hurtado et al., 1998; Solorzano et al., 2000). The shared empirical research shows that African American students' college interactions are full of issues related to microaggressions, societal changes, integration, and a sense of belonging, particularly at Predominantly White Institutions. Despite those generally poor perceptions, researchers formed a common consensus regarding how African American students' support must be systematized and constructed utilizing an asset approach framework. With this in mind, a real commitment to helping Black students would mean introducing a system-wide commitment. In response to learning adjustments pertaining to COVID-19, researchers at the Learning Policy Institute proport that educators must reflexively approach online learning through deeply cultivating relationships with students (Darling-Hammond et al., 2020). Additionally, since in-person interactions are limited, educational facilitators must prioritize authentic, culturally informed approaches to engage students (Darling-Hammond et al., 2020). In this way, the emphasis is placed on approaching and impacting students so that it will be specifically resolved to engage with their support because it satisfies their needs compliantly. Finally, empirical literature suggests there can be efficiency in online career counseling (Pordelan \& Hosseinian, 2020).

Interest in helping Black college students with respect to job counseling in a digital world as a result of a pandemic indicates that improvements to in-person support must be modified. Focusing on helping students immersed in the current standard post-secondary environments, virtual, often means the adjustments must involve changing the way activities are leveraged. As a result, the authors discuss a variety of implications relevant to activities that may empower both students and practitioners. First, practitioners must appropriate knowledge that critically reflects supporting students while enacting practices that speak to the student. That is, practitioners must ask themselves whether their approach helps the student or whether it is hurting the student. Note, too, that such approaches, once 
adopted, must be systematized to maximize impact. Additionally, practitioners must approach their work by integrating an asset-based approach. Finally, while there are no specific models for career services online, there are studies that identify the benefits of providing career counseling online (Venable, 2010; Young, 2019). As such, clinicians' approaches to assisting under-represented students with career support programs should be rooted in the tradition of strategic thought and assetconsciousness and geared towards promoting positive relationships.

\section{CONCLUSION}

This conceptual paper sought to discuss the unintended inequities of the COVID-19 pandemic on job prospects and social capital for students of color. Social capital involves gaining access to networks, knowledge, and opportunities (Museus \& Neville, 2012; Parks-Yancy, 2006; Parks-Yancy, 2012; Yosso, 2005). Students of color arrive on campus with many cultural capital types that researchers and practitioners have not traditionally valued (Yosso, 2005). By and large, underrepresented students have benefitted from additional social capital that is transferred by faculty and university administrators. On the other hand, race and gender have impacted access to social capital and potential returns (Parks-Yancy, 2006). Specifically, ParksYancy (2006) found that limited access to social capital produced inequities that start from the first career post-graduation with lifetime earning implications. As such, graduates' success will depend on innovative collaborations with faculty and other university departments to introduce students earlier to how career services help them accomplish their career goals.

Schoenacher (2009) believes that social capital can be fostered between students through online course discussion threads. Yet, Mays (2016) reports that student to student relationships are difficult to facilitate in online courses, preferring the natural interactions built-in face-to-face classes. Furthermore, Mays (2016) found that online courses failed in cultivating relationships among students due to limited communication and no immediate interaction. Participants reported fewer connections with classmates and less sense of community (Mays, 2016). Falconer and Hays (2006) revealed that Black students are largely unaware of their university career services departments. While this research was conducted prior to the recent response to COVID-19, it may provide some insight into students' current experiences. Awareness of the challenges and divisions created through online instruction calls for deepening relationships throughout campus to reach students in desperate need of services to increase their social capital. This requires 
unconventional approaches to reach students and a desire to cultivate a career readiness culture that exists beyond university career centers.

Given the added barrier of awareness through virtual operations, career services must work to find innovative ways to connect with underrepresented students. Collaborating with student organizations that support underrepresented students to host events will help career services to broaden their reach. Leveraging technology to host virtual mentorship opportunities, virtual networking events, and increasing career services staff competencies of unique challenges faced by underrepresented students are all important pieces to increasing social capital. Engaging in practices that proactively reach out to underrepresented students instead of waiting for students to seek out the assistance of career services will prove beneficial. Additionally, Falconer and Hays (2006) found that the students' motivation to persist and discuss career interests were propelled through their peer friendships. As such, in addition to impacting career outcomes, it is likely that virtual operations will negatively influence retention since there are barriers to building peer relationships. This begs how colleges ensure that relationships are fostered that can benefit both career outcomes and matriculation?

Falconer and Hays (2006) also reveal that Black students have a stigma about seeking help, which would prevent them from building relationships with faculty members and even seeking assistance from university career centers. Faculty members also have an obligation to check biases on the abilities of underrepresented student populations. Furthermore, faculty must educate themselves about students' uneasiness to approach them when they need assistance and take proactive steps to build relationships with students and model positive faculty/student relationships. Guiffrida (2005) calls on faculty to adopt the ideas of "othermothering," which goes beyond providing students with knowledge and access to contacts. Othermothering involves a more profound sense of caring for college students, particularly Black and underrepresented students. As such, faculty should initiate conversations, refer resources, and inform underrepresented students about opportunities when appropriate. Response to COVID-19 does not absolve faculty and practitioners from centering underrepresented students' success and carefully analyzing how institutions' actions impact them.

\section{REFERENCES}

Amundson, N. E., Harris-Bowlsbey, J., \& Niles, S. G. (2009). Essential elements of career counseling: Processes and techniques. Pearson/Merrill.

Bell, D. (1992). Faces at the bottom of the well: The permanence of racism. Basic Books. Bourdieu, P. (1977). Outline of a theory of practice. Cambridge University Press. 
Bureau of Labor Statistics. (2020, September 4th). The Employment situation - July $2020 . \quad$ U.S. Department of Labor. https://www.bls.gov/news.release/pdf/empsit.pdf

Darling-Hammond, L., Schachner, A., Edgerton, A. K., Badrinarayan, A., Cardichon, J., Cookson, P. W., \& Griffith, M. (2020, August 25th). Restarting and reinventing school: Learning in the time of COVID and beyond. Learning Policy Institute. https://learningpolicyinstitute.org/product/restartingreinventing-school-covid-report

Delgado, R. (2003). Crossroads and blind alleys: A critical examination of recent writing about race. Texas Law Review, 82,121-152.

Engelland, B. T., Workman, L., \& Singh, M. (2000). Ensuring service quality for campus career services centers: A modified SERVQUAL scale. Journal of Marketing Education, 22(3), 236-245.

https://doi.org/10.1177/0273475300223007

Falconer, J. W., \& Hays, K. A. (2006). Influential factors regarding the career development of African American college students: A focus group approach. Journal of Career Development, 32(3), 219-233. https://doi.org/10.1177/0894845305279166

Fischer, M. J. (2007). Settling into campus life: Differences by race/ethnicity in college involvement and outcomes. Journal of Higher Education, 78(2), 125-156. https://doi.org/10.1080/00221546.2007.11780871

Gray, R., Vitak, J., Easton, E. W., \& Ellison, N. B. (2013). Examining social adjustment to college in the age of social media: Factors influencing successful transitions and persistence. Computers \& Education, 67, 193207. https://doi.org/10.1016/j.compedu.2013.02.021

Guiffrida, D. (2005). Othermothering as a framework for understanding African American students' definitions of student-centered faculty. Journal of Higher Education https://doi.org/10.1080/00221546.2005.11772305

(76)6,701-723.

Helens-Hart, R. (2019). Career education discourse: Promoting student employability in a university career center. Qualitative Research in Education, 8(1), 1-26. http://dx.doi.org/10.17583/qre.2019.3706

Hurtado, S., Clayton-Pedersen, A.R., Allen, W.R., \& Milem, J.F. (1998). Enhancing Campus Climates for Racial/Ethnic Diversity: Educational Policy and Practice. The Review of Higher Education 21(3), 279-302. https://doi.org/10.1353/rhe.1998.0003

Kochhar, R. (2020, June 11th). Unemployment rose higher in three months of COVID-19 than it did in two years of the Great Recession. Pew Research Center. https://www.pewresearch.org/facttank/2020/06/11/unemployment-rose-higher-in-three-months-of-covid-19than-it-didEducation, stratification, and the academic hierarchy-in-twoyears-of-the-great-recession/

Lang, D. (1984). Education, stratification, and the academic hierarchy. Research in Higher Education, 21, 329-352. 
Maurino, P. S. M. (2007). Looking for critical thinking in online threaded discussions. Journal of Educational Technology Systems, 35(3), 241-260.

Mays, T. (2016). Graduate inquiry: Social capital in online courses. Mid-Western Educational Researcher, 28(2), 162-186.

Miller, M. J., \& Brown, S. D. (2005). Counseling for career choice: Implications for improving interventions and working with diverse populations. Career development and counseling: Putting theory and research to work, 5, 441-465.

Museus, S. D., \& Neville, K. M. (2012). Delineating the ways that key institutional agents provide racial minority students with access to social capital in college. Journal of College Student Development, 53(3), 436-452. https://doi.org/10.1353/csd.2012.0042

Parks-Yancy, R. (2006). The effects of social group membership and social capital resources on careers. Journal of Black Studies, 36(4), 515-545. http://doi.org/10.1177/0021934704273501

Parks-Yancy, R. (2012). Interactions into opportunities: Career management for low-income, first-generation African American college students. Journal of College Student Development, 53(4), 510-523. http://dx.doi.org/10.1353/csd.2012.0052

Pascarella, E. T., \& Terenzini, P. T. (2005). How college affects students: A third decade of research. Jossey-Bass.

Pordelan, N., \& Hosseinian, S. (2020). Design and development of the online career counselling: a tool for better career decision-making. Behaviour \& Information Technology, 1-21. https://doi.org/10.1080/0144929X.2020.1795262

Rankin, S. R., \& Reason, R. D. (2005). Differing perceptions: How students of color and white students perceive campus climate for underrepresented groups. Journal of College Student Development, 46(1), 43-61. https://doi.org/10.1353/csd.2005.0008

Rice, K. G., Lopez, F. G., Richardson, C. M., \& Stinson, J. M. (2013). Perfectionism moderates stereotype threat effects on STEM majors' academic performance. Journal of Counseling Psychology, 60(2), 287-293. https://doi.org/10.1037/a0032052

Roksa, J., \& Whitley, S.E. (2017). Fostering academic success of first-year students: Exploring the roles of motivation, race, and faculty. Journal of College Student Development, 58(3), 333-348. https://doi.org/10.1353/csd.2017.0026

Rosenbaum, J. E., DeLuca, S., Miller, S. R., \& Roy, K. (1999). Pathways into work: Short-and long-term effects of personal and institutional ties. Sociology of Education, 72, 179-196. https://doi.org/10.2307/2673228

Rothstein, R. (2020, April 14th). The coronavirus will explode achievement gaps in education. Economic Policy Institute. https://www.epi.org/blog/thecoronavirus-will-explode-achievement-gaps-in-education/

Schoenacher, S.R. (2009). Building social capital through online class discussions: A little freedom goes a long way. Journal of Educational Technology 
Systems, 37(3) 291-304. https://doi.org/10.2190/ET.37.3.e

Singh, R., Ragins, B. R., \& Tharenou, P. (2008). Who gets a mentor? A longitudinal assessment of the rising star hypothesis. Journal of Vocational Behavior, 74, 11-17. https://doi.org/10.1016/j.jvb.2008.09.009

Solorzano, D., Ceja, M., \& Yosso, T. (2000). Critical race theory, racial microaggressions, and campus racial climate: The experiences of African American college students. Journal of Negro education, 60-73.

Stolzenberg, E. B., Aragon, M. C., Romo, E., Couch, V., McLennan, D., Eagan, M. K., \& Kang, N. (2020). The American Freshman: National Norms Fall 2019. Los Angeles: Higher Education Research Institute, UCLA. https://www.heri.ucla.edu/monographs/TheAmericanFreshman2019.pdf

Venable, M. A. (2010). Using technology to deliver career development services: Supporting today's students in higher education. The career development quarterly, 59(1), 87-96.

Yosso, T. J. (2005). Whose culture has capital? A critical race theory discussion of community cultural wealth. Race Ethnicity and Education, 8(1), 69-91. https://doi.org/10.1080/1361332052000341006

Young, M. (2019). Career Services: Roles beyond job seeking. In J. Higgs, G. Crisp, \& W. Letts (Eds.), Education for Employability (Vol. 2) (pp. 179188). Brill Sense.

EMMANUELA P. STANISLAUS, PhD, is an associate director for the career and talent development department at Florida International University (FIU). She also is an adjunct professor in the FIU higher education administration master's program. Her research centers on the experiences of Black college women, campus climate, first-generation students, and examining intersections of race, ethnicity, and gender. Email: estanis1@fiu.edu

LYNELL S. HODGE, EdD is a practitioner scholar with decades of professional and research experience. Dr. Hodge currently serves as the Assistant Director of Occupancy Management for Housing and Residence Life at the University of Central Florida (UCF). Her expertise includes vicarious/secondary trauma, social justice, and women's equity. She earned her Doctorate from the University of Central Florida in Higher Education and Policy Studies and Master's from The Florida State University in Higher Education. Email: 1ynell@ucf.edu

AMANDA WILKERSON, EdD is Assistant Professor in the Department of Urban Higher Education at University of Central Florida. Email: amanda.wilkerson@ucf.edu 